\title{
SWAMP EELS (Synbranchus sp.) JENIS YANG BARU TERCATAT (NEW RECORD SPECIES) DI DANAU MATANO SULAWESI SELATAN*)
}

\author{
Safran Makmur'), Husnah'1), dan Samuel'1) \\ 1) Peneliti pada Balai Riset Perikanan Perairan Umum, Mariana-Palembang \\ Teregristrasi I tanggal: 27 Maret 2006; Disetujui terbit tanggal: 16 Juni 2006
}

\begin{abstract}
ABSTRAK
Riset keanekaragaman hayati dan bahan perumusan pengelolaan jenis ikan endemik perairan pedalaman di Sulawesi dilakukan pada tahun 2005 di kompleks Danau Malili Kabupaten Luwu Timur Sulawesi Selatan. Dua ekor masapi ditangkap di perairan Danau Matano pada bulan Desember 2005 dengan panjang total 466 dan $384 \mathrm{~mm}$. Belut atau masapi ditangkap dengan tombak dengan cara menyelam pada kedalaman lebih dari $3 \mathrm{~m}$. Berdasarkan pada hasil identifikasi masapi tersebut merupakan jenis Synbranchus sp., famili Synbranchidae. Morfologi Synbranchus sp. sepintas seperti Anguilla sp., hanya pada Synbranchus tidak mempunyai sirip dada, sedangkan perbedaan dengan Monopterus albus, terletak pada septum dan jumlah insang. Perbedaan dengan Synbranchus (Macrotrema) hasil identifikasi Smith (1945) yaitu pada posisi anus dengan pangkal sirip punggung. Sedangkan perbedaan dengan Synbranchus bengalensis yaitu pada perbandingan ukuran panjang kepala dengan panjang ekor. Berdasarkan pada hasil penelitian sebelum di Danau Matano, Synbranchus sp. merupakan jenis yang digolongkan new record species di Danau Matano. Berdasarkan pada perbedaan-perbedaan dengan jenis Synbranchidae lain dan mengingat tingkat endemisitas Danau Matano yang tinggi ada kemungkinan jenis tersebut merupakan jenis endemik di Danau Matano
\end{abstract}

KATA KUNCI: belut, Synbranchus sp., spesies endemik, Danau Matano, Sulawesi Selatan

\section{PENDAHULUAN}

Belut (swamp eels) merupakan jenis ikan yang tidak bersisik dan mempunyai bentuk tubuh bulat memanjang (angguilliform body), tidak mempunyai sirip perut (pelvic) dan sirip dada (pectoral). Sirip punggung (dorsal), ekor, dan sirip anal menjadi satu, dengan tubuh yang licin sehingga penampilan sekilas seperti ular. Distribusi belut terutama pada daerah tropis Afrika, Asia, dan Amerika. Habitat utama belut adalah di perairan yang berlumpur seperti sawah, kolam, sungai, dan dasar perairan (demersal). Pada bagian bawah kepala terdapat lubang merupakan tutup insang yang menjadi satu lipatan tunggal di mana di dalam rongga tersebut terdapat insang. Morfologi mulut besar dan kuat dengan deretan gigi, hal tersebut sesuai dengan kebiasaan makan yang bersifat karnivora. Mempunyai sepasang mata kecil dan warna tubuh coklat tua atau coklat kemerahan dengan warna yang lebih muda pada bagaian perut atau bawah tubuh. Aktif mencari makan pada malam hari (nokturnal) dengan makanan utama adalah ikan kecil, cacing, udang, dan hewan kecil lain (Anonimus a, 2006; Anonimus b, 2006). Berdasarkan pada Kottelat et al. (1993), famili Synbranchidae mempunyai 2 genus yaitu Monopterus (Fluta) dan Synbranchus (Ophisternon). Di Indonesia jenis belut cukup mudah di temukan dan bahkan belut sudah banyak dibudidayakan karena merupakan jenis ikan konsumsi yang cukup digemari. Di Danau Matano, telah diidentifikasi jenis Monopterus albus, dan belum pernah tercatat atau terdata jenis lain. Pada riset keanekaragaman sumber daya ikan di Sulawesi Selatan, team riset dari Pusat Riset Perikanan Tangkap berhasil mendapatkan contoh (2 ekor) ikan jenis belut (swamp eels) yang mempunyai banyak perbedaan dengan jenis yang selama ini dikatakan Monopterus albus.

\section{Lokasi Pengambilan Contoh}

Riset ini merupakan bagian dari riset keanekaragaman hayati dan bahan perumusan pengelolaan jenis ikan endemik perairan pedalaman di Sulawesi yang lakukan pada tahun 2005 di kompleks Danau Malili Kabupaten Luwu Timur Sulawesi Selatan (Gambar 1 dan 2). Contoh diperoleh dari hasil tangkapan nelayan di Danau Matano. Identifikasi contoh dilakukan dengan menggunakan buku-buku Weber \& Beaufort (1913); Smith (1945); Kottelat et al. (1993). Di samping itu, juga dilakukan karakterisasi morfologi.

Contoh ikan Synbranchus sp. berhasil ditangkap di perairan Danau Matano pada bulan Desember 2005. Ikan belut Synbranchus sp. ditangkap oleh nelayan di perairan Danau Matano dengan kedalaman lebih dari $3 \mathrm{~m}$ dengan dasar danau yang agak berlumpur. Belut Synbranchus sp. sangat susah untuk 


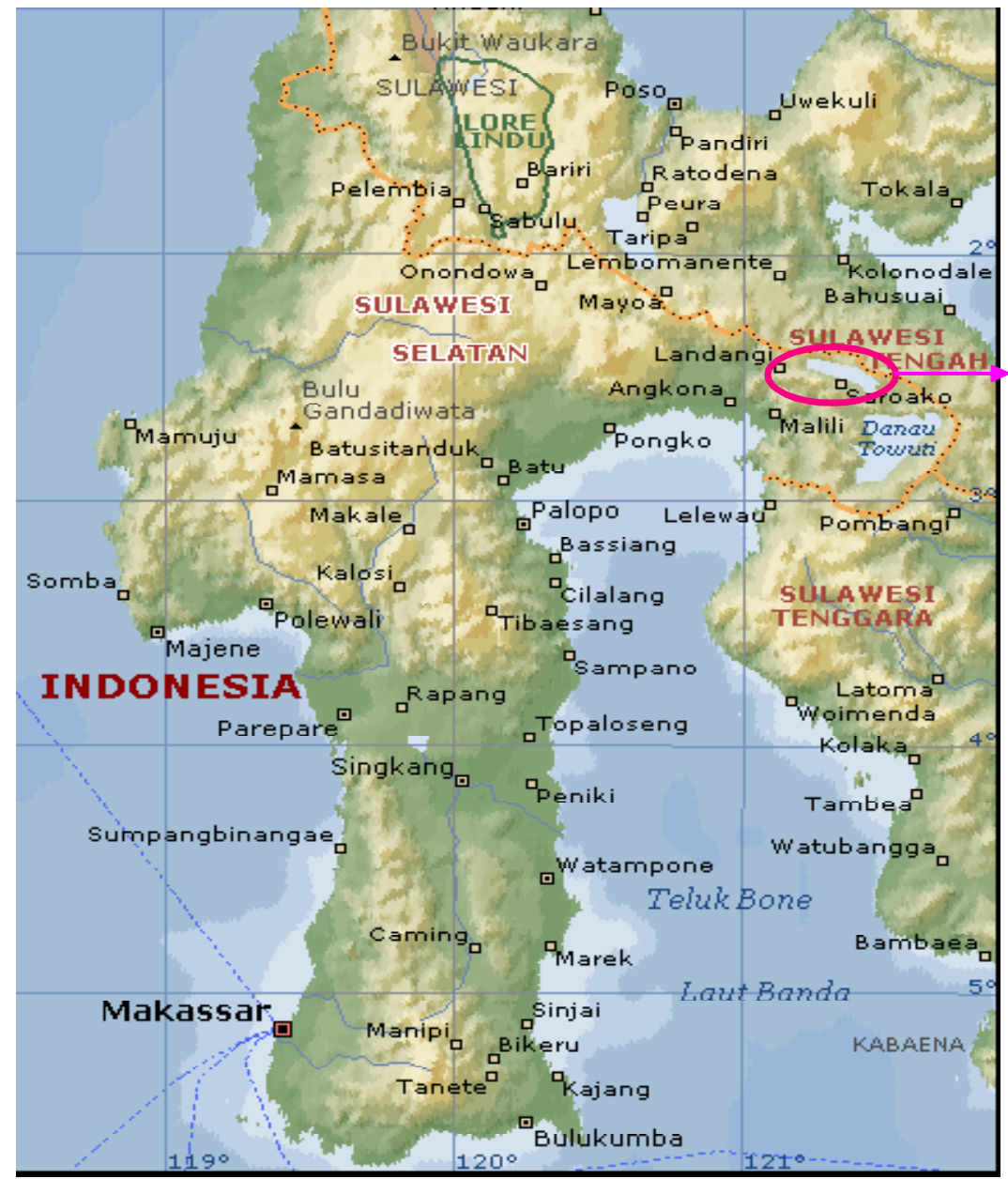

Lokasi pengambilan contoh Synbranchus sp. di Danau Matano.

Gambar 1. Peta lokasi penelitian Danau Matano Sulawesi Selatan.
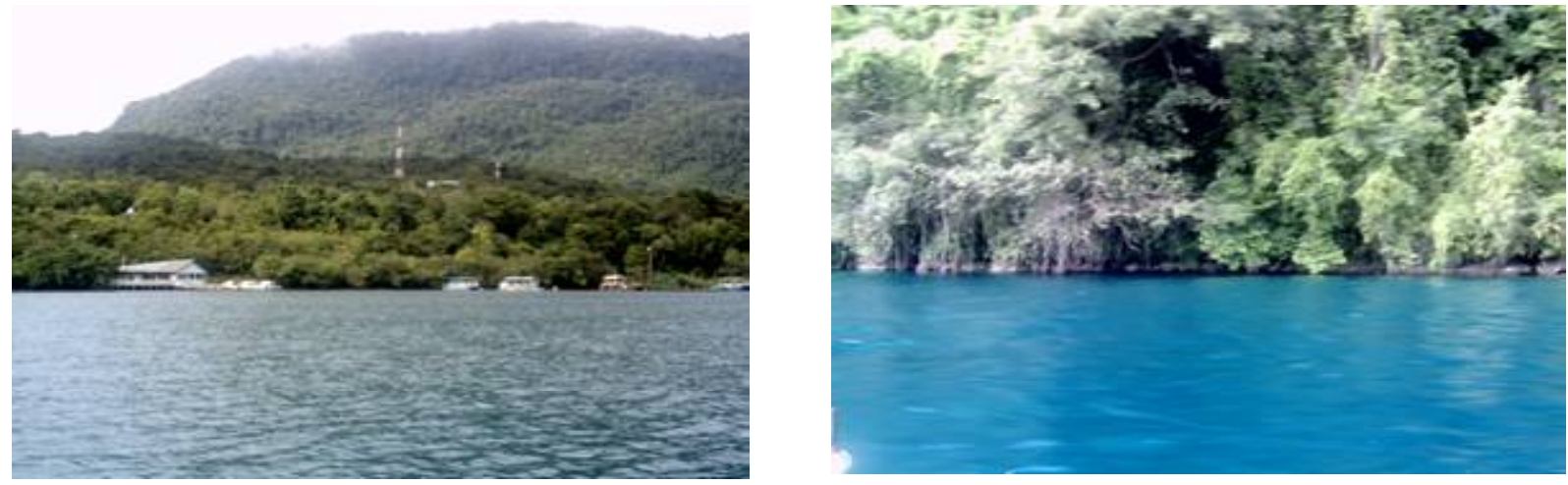

Gambar 2. Perairan Danau Matano Kabupaten Luwu Timur Sulawesi Selatan.

ditangkap, hidup di dasar perairan dan aktif pada malam hari (nocturnal). Nelayan menangkap belut dengan cara menyelam ke dalam perairan, alat tangkap yang digunakan adalah tombak, hal ini dikarenakan belut hidup di dalam lumpur dan cukup susuh untuk di tangkap dengan menggunakan alat tangkap lain. Akibat belut yang tertangkap mengalami luka-luka pada bagian tubuh.
Menurut nelayan setempat belut ini disebut masapi. Secara sepintas, morfologi Synbranchus sp. (swamp eels) mirip dengan sidat (Anguilla sp.) terutama pada bentuk kepala, ekor, sirip, dan warna tubuh, tetapi jika di perhatikan lebih lanjut ada beberapa ciri umum sidat yang tidak dimiliki oleh belut Synbranchus. Bagian tersebut adalah sirip dada atau sering disebut telinga. 


\section{Klasifikasi dan karakterisasi}

Klasifikasi belut Danau Matano berdasarkan pada Smith (1945); Weber \& Beauford (1913); Kottelat et al. (1993) adalah:
Kelas
: Actinopterygii
Ordo : :Synbranchiformes
Sub Ordo : Synbranchoidei

\section{Famili : Synbranchidae \\ Genus : Synbranchus \\ Species : Synbranchus sp.}

Hasil karakterisasi (Gambar 3), menunjukkan jenis belut yang ditemukan di Danau Matano merupakan jenis yang belum pernah diidentifikasi. Hasil penelitian selama ini di Danau Matano ditemukan belut famili

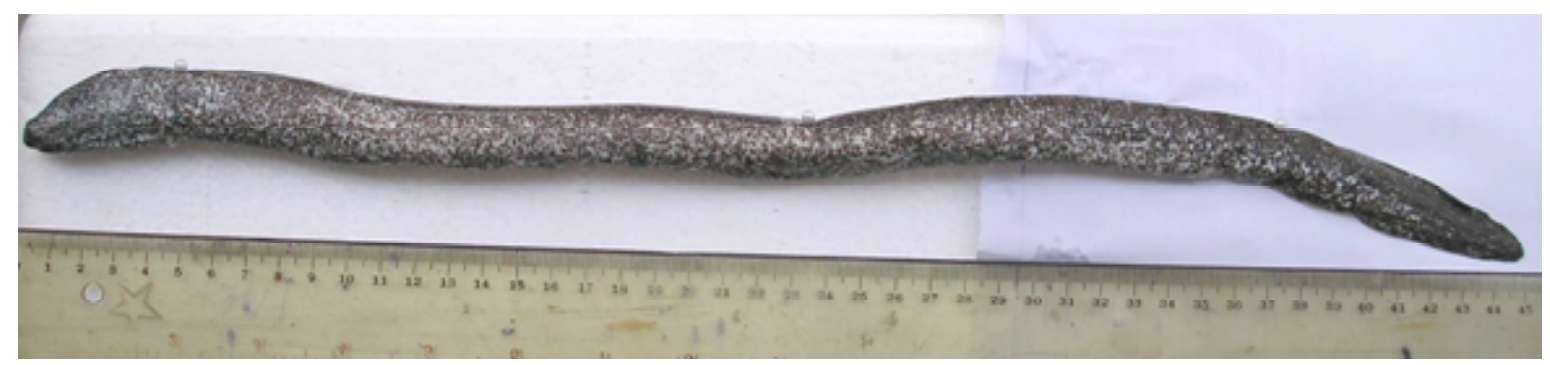

Gambar 3. Synbranchus sp. di Danau Matano Sulawesi Selatan.

Synbranchidae yaitu, jenis Monopterus albus. Monopterus albus dengan jenis Synbranchus sp. yang didapatkan di Danau Matano pada saat survei bulan Desember 2005 mempunyai perbedaan yang sangat jelas. Perbedaan tersebut dapat dilihat dari warna di mana jenis Monopterus albus berwarna lebih hitam dan bagian bawah yang lebih terang sedangkan
Synbranchus sp. berwarna coklat tua dengan bintik atau bercak putih. Lebih jelas lagi pada bentuk lubang atau sekat (septum) dan jumlah insang (gill raker) di mana pada Monopterus albus sekat berbentuk hampir segitiga dan jumlah gill raker 3 pasang sedangkan pada Synbranchus sp. bentuk sekat setengah lingkaran dan jumlah insang 4 pasang (Gambar 4 dan 5).
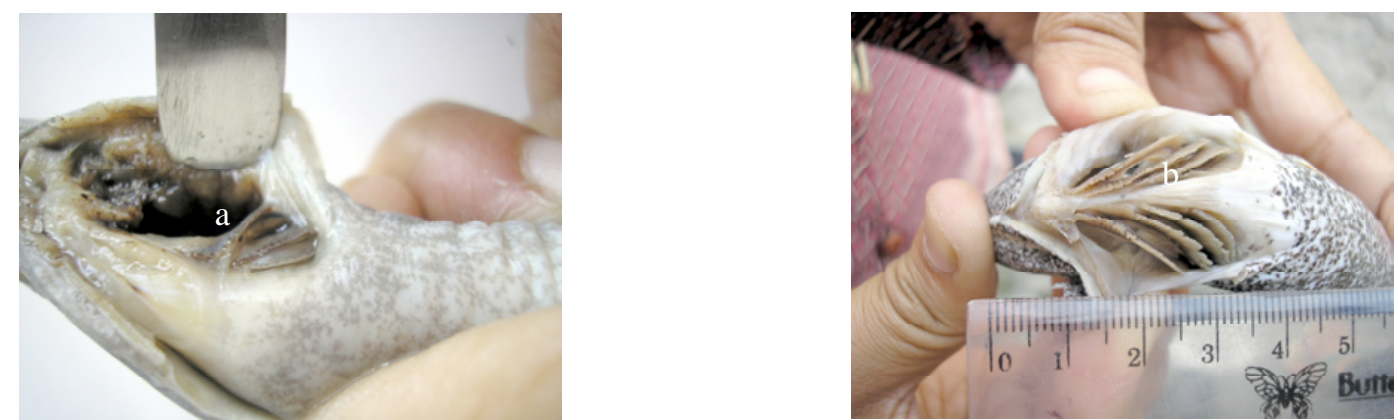

Gambar 4. Jumlah insang (gill raker) 3 pasang pada Monopterus albus (a) dan 4 pasang pada Synbranchus sp. (b).
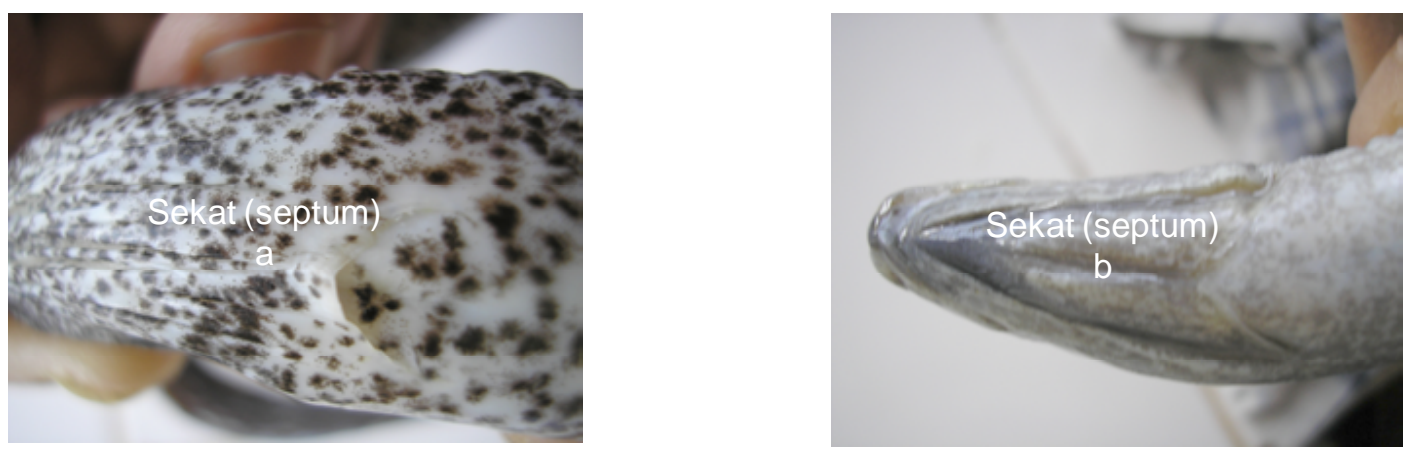

Gambar 5. Bagian bawah kepala dan sekat (septum) Synbranchus sp. (a) dan Monopterus albus (b). 
Perbedaan Jenis Synbranchus sp. dari Danau Matano dengan jenis Synbranchus (Macrotrema) hasil identifikasi Smith (1945), yaitu pada posisi pangkal sirip punggung. Pada Macrotrema posisi pangkal sirip punggung sama atau sejajar dengan anus sedangkan pada Synbranchus sp. letak pangkal sirip punggung di depan anus. Sedangkan perbedaan dengan Synbranchus bengalensis yaitu perbandingan ukuran panjang kepala dengan panjang ekor 4 kali dari panjang ekor Synbranchus sp. per-bandingan hanya lebih kurang 2,5 kali (Gambar 6).

Berdasarkan pada hasil penelitian sebelum di Danau Matano, jenis ikan masapi (Synbranchus sp.) di Danau Matano tersebut belum tercatat, sehingga jenis ini dapat digolongkan sebagai new record species di Danau Matano. Di samping itu, mengingat tingkat endemisitas Danau Matano yang tinggi juga ada kemungkinan jenis tersebut merupakan jenis endemik. Penelitian dan indentifikasi lebih lanjut perlu dilakukan untuk memastikan hal tersebut.

\section{Karakterisasi}

Dari hasil pengukuran 2 ekor contoh Synbranchus sp. diperoleh data-data karakteristik morfologi sebagai berikut (Tabel 1).

Masapi atau belut Synbranchus sp. yang di peroleh di Danau Matano secara ekonomis nilai belum ada bagi masyarakat setempat, karena berdasarkan pada wawancara yang dilakukan dengan masyarakat

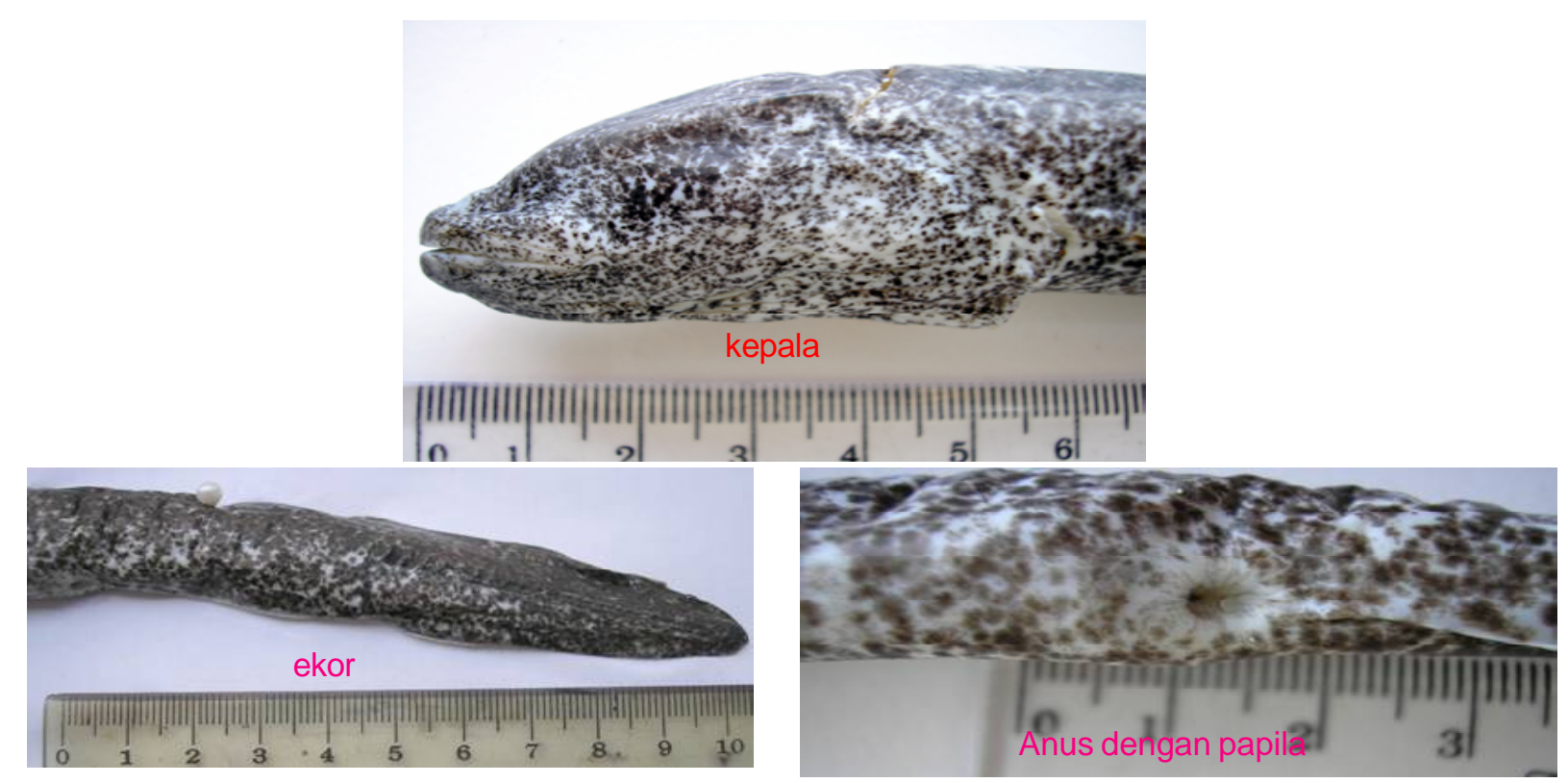

Gambar 6. Bagian kepala, ekor dan anus Synbranchus sp.

Tabel 1. Beberapa karakterisasi morfologi Synbranchus sp. dari Danau Matano Sulawesi Selatan

\begin{tabular}{lcc}
\hline \multicolumn{1}{c}{ Karaktersitik } & Contoh 1 & Contoh 2 \\
\hline Panjang total $(\mathrm{mm})$ & 466 & 384 \\
Panjang kepala $(\mathrm{mm})$ & 48,5 & 42,4 \\
Diameter mata $(\mathrm{mm})$ & 0,29 & 0,21 \\
Panjang sirip belakang dubur $(\mathrm{mm})$ & 99,7 & 93,9 \\
Panjang sirip punggung $(\mathrm{mm})$ & 113,7 & 98,6 \\
Tinggi badan (mm) & 19,7 & 15,5 \\
Panjang mulut bawah $(\mathrm{mm})$ & 15,4 & 11,5 \\
Panjang mulut atas $(\mathrm{mm})$ & 15,4 & 12,3 \\
Panjang antara mata-pangkal mulut $(\mathrm{mm})$ & 0,64 & 0,49 \\
Panjang dari ujung mulut sampai lubang insang $(\mathrm{mm})$ & 34,5 & 29,6 \\
Panjang lubang insang (mm) & 12,2 & 8,4 \\
\hline Warna & Coklat tua dengan & Coklat tua dengan bintik \\
& bintik putih & putih \\
\hline
\end{tabular}


setempat, pada umumnya enggan untuk mengkonsumsi ikan belut ini karena bentuk dan morfologi ikan tersebut yang tampak sepintas seperti ular. Selain itu, jenis ini sangat sulit untuk ditangkap dan populasi juga di alam tidak banyak. Secara ekologis, Synbranchus sp. yang merupakan jenis ikan karnivora keberadaan di alam merupakan penyeimbang ekologi dalam hubungan dengan rantai makanan.

\section{KESIMPULAN}

Ikan masapi yang ditemukan di Danau Matano Sulawesi Selatan adalah dari jenis Synbranchus sp., merupakan jenis yang baru tercatat (new record species) di Danau Matano. Berdasarkan pada perbedaan-perbedaan dengan jenis Synbranchidae lain dan mengingat tingkat endemisitas Danau Matano yang tinggi, kemungkinan jenis tersebut merupakan jenis endemik di Danau Matano.

\section{UCAPAN TERIMA KASIH}

Kepada Bapak Dahlan-Nelayan Desa Soroako Kecamatan Nuha Kabupaten Luwu Timur; Bapak Sidarta Gautama-Teknisi Balai Riset Perikanan Perairan Umum; dan Ibu Ir. Eti Nurhayati di Balai Riset
Perikanan Perairan Umum Palembang yang telah mendukung jalannya kegiatan riset ini.

\author{
Persantunan: \\ Hasil dari kegiatan riset Wallacea T.A. 2005 di \\ Pusat Riset Perikanan Tangkap
}

\section{DAFTAR PUSTAKA}

Anonimus a. 2006. Monopterus albus swamp eels. http://fishbase.sinica.edu.tw/summary/ SpeciesSummary.php?id=4663.

Anonimus b. 2006. Synbranchidae-swamp eels. http:/ /animaldiversity.ummz.umich.edu/site/accounts/ \begin{tabular}{lllllllllllllll}
\hline $\mathrm{c}$ & $\mathrm{I}$ & $\mathrm{a}$ & $\mathrm{s}$ & $\mathrm{s}$ & $\mathrm{i}$ & $\mathrm{f}$ & $\mathrm{i}$ & $\mathrm{c}$ & $\mathrm{a}$ & $\mathrm{t}$ & $\mathrm{i}$ & 0 & $\mathrm{n}$ & / \\
\hline
\end{tabular} Synbranchidae.html\#Synbranchidae.

Kottelat, M., A. J. Whitten., S. N. Kartikasari., \& S. Wirjoatmodjo. 1993. Ikan air tawar Indonesia bagian barat dan Sulawesi. Periplus Editions Limited. Jakarta. 293 hal.

Smith. 1945. The fresh water fishes of Siam or Thailand Smithsonian. United States National Museum Bulletin Washington. USA. 57-59 p.

Weber, M. \& L. F. DeBeaufort. 1913. The Fishes of Indo-Australia Archipelago III. Brill. Leiden. 